http://dx.doi.org/10.35630/2199-885X/2020/10/2.32

\title{
STUDY OF ELASTIC ELEMENTS OF LOWER JAW EXOSKELETON
}

\section{Alexander Vorobyev $v^{1 \otimes}(\mathbb{D})$, Denis Dyachenko ${ }^{1}$, Yuliya Makedonova ${ }^{2}$, Karen Sargsyan ${ }^{3}$ (D), Svetlana Dyachenko ${ }^{2}$ (1)}

\author{
${ }^{1}$ Department of Operative Surgery and Topographic Anatomy, \\ ${ }^{2}$ Dentistry Institute, \\ ${ }^{3}$ Department of Surgical Dentistry and Oral and Maxillofacial Surgery, \\ Volgograd State Medical University, Volgograd, Russia
}

ABSTRACT — THE AIM OF THIS STUDY is to prove compensatory abilities of anti-gravity elastic traction of lower jaw exoskeleton. MATERIALS AND METHODS. The test involved 97 volunteers who were divided into 3 groups depending on their level of physical activity. In each group, all participants were randomly divided into 2 subgroups: without load compensation and with load compensation on the lower jaw. The load test was carried out for each participant using a special device simulating a one-way load on the lower jaw. Load compensation was made by elastic elements. Registration of subjects 'postures was carried out by the method of photometry of subjects' spines with pre-marked markers of Th-1 and L-1 vertebrae. Photos were analyzed in Photoshop CS. For this purpose, the line between the markers Th-1 and L-1 has been drawn. Analysis of the results was carried out on the angle of deviation of the vertebral column before and after the study. RESULTs. In the course of the study on volunteers it was found that the one-sided load on the lower jaw is reflected on the posture of the tested person, but elastic elements are able to compensate for the one-sided load and minimize the angle of inclination of the vertebral column. It has also been found that the angle of inclination is affected by the initial physical preparation to the test. Conclusion. During the study, the compensatory abilities of the anti-gravity elastic pull of the lower jaw exoskeleton have been proved.

KEYW ORDS - posture, exoskeleton, photometry, load, lower jaw.

\section{INTRODUCTION}

Diagnostics in dentistry, on the one hand, has its own specifics; on the other hand, it is based on general medical research methods. All diagnostic methods and tests to varying degrees are objective and informative, have their sensitivity, specificity and reproducibility. [1-12]. One of the most common injuries to the bones of the facial part of the head is fractures of the lower jaw $[13,14]$. In view of surgical and cosmetic features of carrying out operations in maxillofacial
Received 20 April 2020; Received in revised form 28 May 2020; Accepted 5 June 2020

area [15], for restoration of functional activity at a fracture of the lower jaw we developed the device an exoskeleton of the lower jaw (patent No. 2655086 of 17.07.2017) - the device consisting of the device of external fixing of otlomk of bones, which is fixed on them by means of osteoclamps, a submandibular arch and a head-mounted hat connected by anti-gravitational elastic elements (Fig. 1).

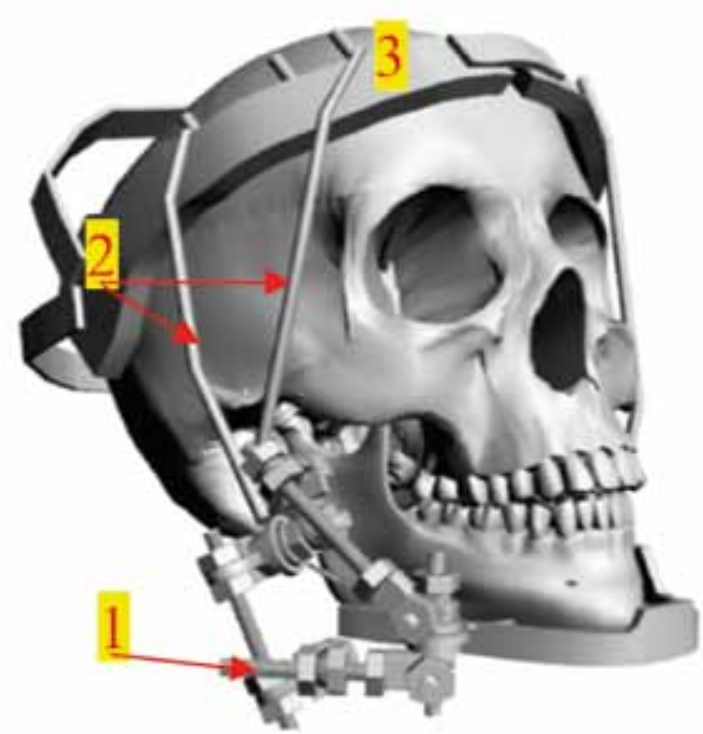

Fig. 1. Exoskeleton of the lower jaw. 1 - external fixation device, 2 elastic elements, 3- head cap

\section{MATERIALS AND METHODS}

In order to model the one-way load and analyze the possibility of its compensation, a special device was used consisting of parallel plates: 1 - a plastic individual impression spoon obtained by printing on a $3 \mathrm{D}$ printer (Fig. 2.1), placed in the oral cavity and 2 - an arc with slots for the attachment of a weight of $0.3 \mathrm{~kg}$, located on the lower edge of the lower jaw (Fig. 2.2). Parts of the device are interconnected by rods (Fig. 2.3) [15].

The study was conducted with the participation of 97 volunteers of both sexes ( 54 female and 43 male) between the ages of 18 and 34 who had previously been acquainted with the trial, and the voluntary informed consent of the patient to participate in the study was obtained. The main criteria of exclusion 


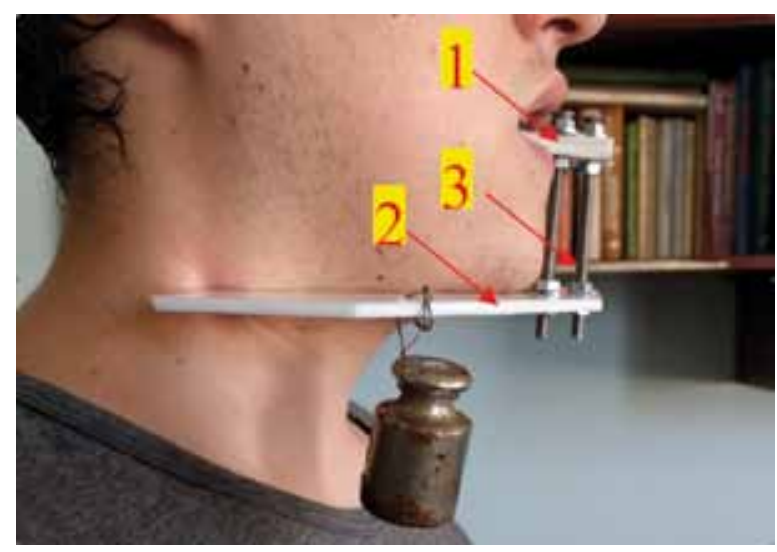

Fig. 2. Load simulation Device. 1 - Plastic individual impression spoon, 2 - Arc with slots for cargo fastening, 3 - Connecting rods

were: refusal to undergo the whole scope of research provided for in the protocol, presence of inflammatory processes in the maxillofacial region, disabled persons of 1-3 groups, and other socially vulnerable groups of the population. Before the trial, all participants underwent an anonymous questionnaire, the results of which were divided into 3 groups depending on the level of their physical activity.

In each of the groups, all subjects were divided into 2 subgroups randomly. Each participant was modeled a one-way load on the lower jaw $(300 \mathrm{~g})$ for 30 minutes. Participants of the first subgroups did not have load compensation devices, and participants of the second subgroups wore a special head cap, to which elastic elements compensating for one-way load were attached (Fig. 3).

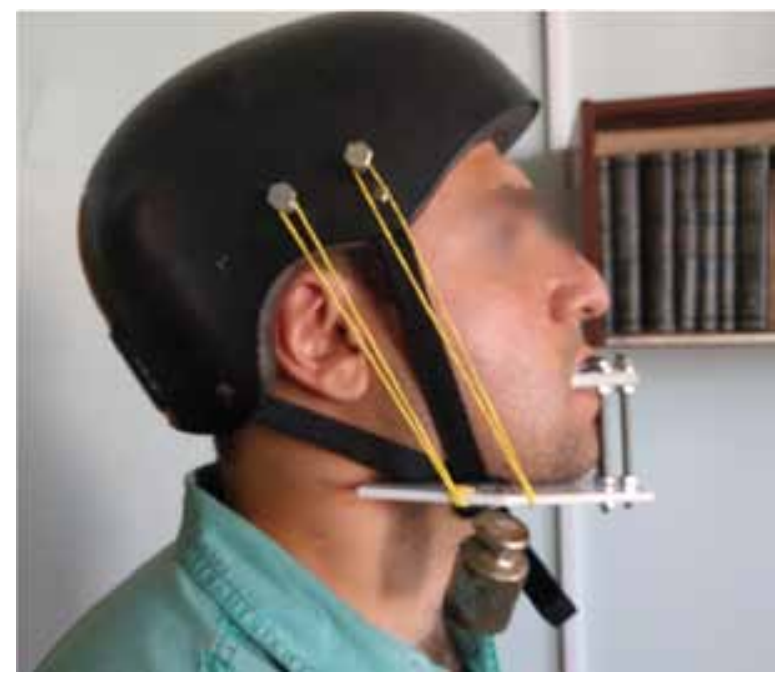

Fig. 3. Elastic elements that compensate for one-way load
The effectiveness of the pathological load compensation was evaluated by anthropometry. For this purpose, markers were applied to the skin of the participants 'back in the area of acute processes of vertebrae Th- 1 and L-1. With the help of a stationary camera and accurate positioning of the test person in front of the camera, the postura (pose taken by the person) was photographed before the beginning of the study and after 30 minutes of wearing the apparatus. Photos were analyzed in Photoshop CS. To do this, the program drew a line between the Th-1 markers and the L-1 for pshots up to (Fig. 4.1) and after the test (Fig. 4.2), the lines were aligned and the inclination angle between the formed straight lines was calculated (Fig. 4.3).

\section{RESULTS}

The results of the study are shown in Table 1 . The table shows that the angle of inclination in a group with a high level of physical training without load compensation is 2.3 times less relative to a group with a low level of training and 1.4 times less relative to an average level of physical training. At the same time, the statistical significance of the differences is noted between the groups. Patients with an average level of physical training also show statistical significance of differences relative to people with a low level (1.6 times less, at $\mathrm{p}<0.05)$. In load compensation, there is also a statistically significant difference between high and medium training relative to subjects with low training, with a minimum angle of inclination in people with high physical training $($ at $\mathrm{p}<0.05)$.

\section{DISCUSSION}

In the course of the study on volunteers it was found that the one-way load $(300 \mathrm{~g})$ for 30 minutes on the lower jaw is reflected on the post of the tested person, but elastic rods are able to compensate for the one-way load and minimize the angle of inclination. It has also been found that the angle of inclination is influenced by the initial physical training of the subject - volunteers with a high level of physical training much more easily carried the load both by subjective and objective criteria. All this shows that elastic rods used to compensate for the load are able to fully ensure the adequate functioning of the human bone-muscle system as a whole.

\section{CONCLUSION}

During the study, the compensatory abilities of the anti-gravity elastic pull of the lower jaw exoskeleton have been proved. The design of the apparatus enables not only to achieve a reponiating effect, but also allows the patient to maintain the usual lifestyle and social orientation in society. 
Table 1. Angle of inclination, in degrees, ${ }^{\circ}$

\begin{tabular}{l|l|l|l}
\hline $\begin{array}{l}\text { Level of physi- } \\
\text { cal training of } \\
\text { the respondent }\end{array}$ & $\begin{array}{l}\text { High level } \\
\text { of physical } \\
\text { training }\end{array}$ & $\begin{array}{l}\text { Average level } \\
\text { of physical } \\
\text { training }\end{array}$ & $\begin{array}{l}\text { Low level } \\
\text { of physical } \\
\text { training }\end{array}$ \\
\hline $\begin{array}{l}\text { Without } \\
\text { compensation } \\
\text { of loading }\end{array}$ & $1,02 \pm 0,05^{*}$ & $1,47 \pm 0,08^{*}$ & $2,35 \pm 0,11^{*}$ \\
\hline $\begin{array}{l}\text { With com- } \\
\text { pensation of } \\
\text { loading }\end{array}$ & $0,03 \pm 0,01^{*}$ & $0,15 \pm 0,01^{*}$ & $0,23 \pm 0,02^{*}$ \\
\hline
\end{tabular}

Note: * statistical significance of differences between comparison groups relative to group with low level of physical training, at $p<0.05$

\section{REFERENCES}

1. ShKarin V.V., Grinin V.M., Khalfin R.A., DMitrienko S.V., Domenyuk D.A. Specific features of grinder teeth rotation at physiological occlusion of various gnathic dental arches / / Archiv EuroMedica. 2019. Vol. 9; 2: 168-173. https://doi. org/10.35630/2199-885X/2019/9/2/168

2. ShKarin V.V., IVANov S.Yu., DMitrienko S.V., DOMENYUK D.A., LEPILIN A.V., DOMENYUK S.D. Morphological specifics of craniofacial complex in people with various types of facial skeleton growth in case of transversal occlusion anomalie // Archiv EuroMedica. 2019. Vol. 9; 2:5-16. https://doi. org $/ 10.35630 / 2199-885 \mathrm{X} / 2019 / 9 / 2 / 5$

3. ShKarin V.V., Grinin V.M., Khalfin R.A., DMitrienko S.V., Domenyuk D.A. Specific features of transversal and vertical parameters in lower molars crowns at various dental types of arches // Archiv EuroMedica. 2019. Vol. 9; 2: 174-181. https:// doi.org/10.35630/2199-885X/2019/9/2/174

4. Domenyuk D.A., Shkarin V.V., Porfiriadis M.P., DMitrienko D.S., DMitrienko S.V. Classification of facial types in view of gnathology // Archiv EuroMedica, 2017. Vol. 7 (1). P. 8-13.

5. Dmitrienko S.V., Domenyuk D.A., Melekhov S.V., Domenyuk S., WeISHEIM L.D. Analytical approach within cephalometric studies assessment in people with various somatotypes // Archiv EuroMedica. 2019. Vol. 9; 3: 103-111. https://doi. org/10.35630/2199-885X/2019/9/3.29

6. DMitrienko S.V., Fomin I.V., Domenyuk D.A., KondRATYUK A.A., SubBOTIN R.S. Enhancement of research method for spatial location of temporomandibular elements and maxillary and mandibular medial incisors // Archiv EuroMedica. 2019. Vol. 9 (1) P. 38-44. https://doi.org/10.35630/2199$885 \mathrm{X} / 2019 / 9 / 1 / 38$

7. Dmitrienko S., Domenyuk D., Tefova K., Dmitrienko T., Domenyuk S., Kondratyeva T. Modern x-ray diagnostics potential in studying morphological features of the temporal bone mandibular fossa // Archiv EuroMedica. 2020. Vol. 10 (1). P. 116-125. https://doi.org/10.35630/2199$885 \mathrm{X} / 2020 / 10 / 36$

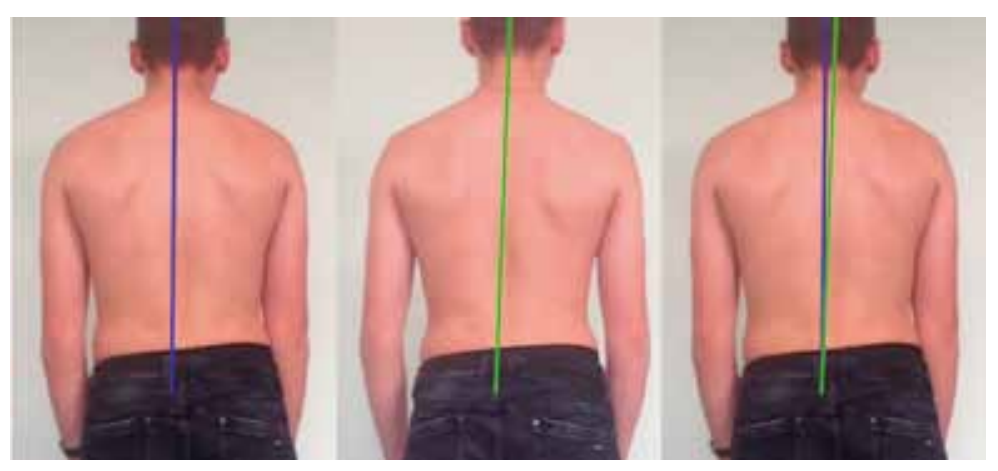

Fig. 4. 1 - Line between the Th-1 and L-1 markers before the study, 2-Line between the Th-1 and L-1 markers after the study, 3 - Align the lines and calculate the angle between them

8. Domenyuk D., DMitrienko S., Domenyuk S., Harutyunyan Yu. Structural arrangement of the temporomandibular joint in view of the constitutional anatomy // Archiv EuroMedica. 2020. Vol. 10 (1). P. 126-136. https://doi.org/10.35630/2199$885 \mathrm{X} / 2020 / 10 / 37$

9. Domenyuk D. A., KorobKeEv A. A., DMitrienko S. V., KorobkeEva YA. A., Grinin V. M., ShKarin V. V. Anatomical and topographical features of temporomandibular joints in various types of mandibular arches. Medical News of North Caucasus. 2019;14(2):363-367. DOI - http://dx.doi. org/10.14300/mnnc.2019.14089 (In Russ.)

10. Korobkeev A.A., Domenyuk D.A., ShKarin V.V., Dmitrienko S.V. Types of facial heart depth in physiological occlusion. // Medical news of North Caucasus. 2018. - Vol. 13 (4) - P. 627-630. (In Russ., English abstract). DOI - https://doi.org/10.14300/ mnnc.2018.13122.

11. Korobkeev A.A., Domenyuk D.A., ShKarin V.V., DMitrienKo S.V., WeISHEIM L.D., KonNOV V.V. Anatomical features of the interdependence of the basic parameters of the dental arches of the upper and lower jaws of man. Medical news of North Caucasus. 2018. Vol. 13. - № 1-1. - P. 66-69. (In Russ., English abstract). DOI - https://doi.org/10.14300/mnnc.2018.13019

12. ShKarin V.V., Grinin V.M., Khalfin R.A., DMitrienko S.V., Domenyuk D.A. Specific features of joint space in patients with physiological occlusion on computed tomogram head image // Archiv EuroMedica. 2019. Vol. 9; 2: 182-183. https:// doi.org/10.35630/2199-885X/2019/9/2/182

13. Afanas'ev V.V. Trauma of the maxillofacial area: manual. M.; GEOTAR-Media, 2010. 156 p.

14. Vorobyov A.A., Chigrova N.A., Pylaeva I.O., BARINOVA E.A. Cosmetic anatomy of the person. ELBI-SPb, 2017.279 p.

15. Vorobyov A.A., Mikhalchenko D.V., SARgsyan K.A., Dyachenko D.Yu., DyaChenko S.V. Analysis of the compensatory capabilities of the elastic elements of the apparatus exoskeleton of the lower jaw. Tauride Medical and Biological Bulletin, 2018. 18-23 p. 